OPEN ACCESS

Edited by:

Cheng-Chia Yu,

Chung Shan Medical

University, Taiwan

Reviewed by:

Chih Yuan Fang,

Taipei Medical University, Taiwan

ChihYu Peng,

Erasmus Medical Center, Netherlands

*Correspondence:

Chung-Ji Liu

liucjliu3229@gmail.com

Specialty section:

This article was submitted to Head and Neck Cancer,

a section of the journal

Frontiers in Oncology

Received: 12 September 2019 Accepted: 22 November 2019 Published: 06 December 2019

Citation:

Lin L-H, Chang K-W, Cheng H-W and Liu C-J (2019) SMAD4 Somatic Mutations in Head and Neck Carcinoma Are Associated With Tumor Progression

Front. Oncol. 9:1379.

doi: 10.3389/fonc.2019.01379

\section{SMAD4 Somatic Mutations in Head and Neck Carcinoma Are Associated With Tumor Progression}

\author{
Li-Han Lin ${ }^{1}$, Kuo-Wei Chang ${ }^{2,3}$, Hui-Wen Cheng ${ }^{1}$ and Chung-Ji Liu ${ }^{3,4 *}$ \\ ${ }^{1}$ Department of Medical Research, MacKay Memorial Hospital, Taipei, Taiwan, ${ }^{2}$ Department of Stomatology, Taipei Veterans \\ General Hospital, Taipei, Taiwan, ${ }^{3}$ School of Dentistry, Institute of Oral Biology, National Yang-Ming University, Taipei, Taiwan, \\ ${ }^{4}$ Department of Oral and Maxillofacial Surgery, Taipei MacKay Memorial Hospital, Taipei, Taiwan
}

As the incidence and the mortality rate of head and neck squamous cell carcinoma (HNSCC) is increasing worldwide, gaining knowledge about the genomic changes which happen in the carcinogenesis of HNSCC is essential for the diagnosis and therapy of the disease. SMAD4 (DPC4) is a tumor suppressor gene. It is located at chromosome 18q21.1 and a member of the SMAD family. Which mediates the TGF- $\beta$ signaling pathway, thereby controlling the growth of epithelial cells. In the study presented here, we analyzed tumor samples by multiplex PCR-based next-generation sequencing (NGS) and found deleterious mutations of SMAD4 in $4.1 \%$ of the tumors. Knock-down experiments of endogenous and exogenous SMAD4 expression demonstrated that SMAD4 is involved in the migration and invasion of HNSCC cells. Functional analysis of a missense mutation in the $\mathrm{MH} 1$ domain of SMAD4 may be responsible for the loss of function in suppressing tumor progression. Missense SMAD4 mutations, therefore, could be useful prognostic determinants for patients affected by HNSCCs. This report is the first study where NGS analysis based on multiplex-PCR is used to demonstrate the imminent occurrence of missense SMAD4 mutations in HNSCC cells. The gene analysis that we performed may support the identification of SMAD4 mutations as a diagnostic marker or even as a potential therapeutic target in head and neck cancer. Moreover, the analytic strategy proposed for the detection of mutations in the SMAD4 gene may be validated as a platform to assist mutation screening.

Keywords: head and neck cancer, loss of heterozygosity, SMAD4, somatic mutation, survival

\section{INTRODUCTION}

Head and neck squamous cell carcinomas (HNSCC), which include oral squamous cell carcinomas, are the sixth most prevalent malignancy worldwide $(1,2)$. The pathogenesis of HNSCC is affected by many molecular factors, among them e.g., mutations in TP53, and genes related to PIK3CA and Notch family signaling (3-9). The role which these factors are playing in the progression of the tumors remains unclear to a wide extent $(3,4,6,10,11)$. Although the knowledge on head and neck carcinogenesis has improved a lot in the past 40 years and many innovations in surgery as well as chemo- and radiotherapy have been made, the survival rates for many HNSCC types 
have not improved considerably (2). Recent developments in high-throughput, next-generation parallel sequencing technologies are facilitating sensitive detection, and quantification of genetic alterations. New insights in the molecular basis of HNSCC progression have been provided by whole-exome sequencing (WES) $(8,12,13)$. The analysis of WES data which was obtained from The Cancer Genome Atlas (TCGA) $(6,14)$ pointed to novel genes with significant mutations and underlined the complex molecular pathogenesis of HNSCC, which includes a high degree of heterogeneity between tumors (15).

SMAD4 is a transcription factor of the SMAD family which takes part in TGF- $\beta$ signaling. SMAD4 stands for SMA- and MAD-related protein 4 , other names are SMAD family member 4, Deleted in Pancreatic Cancer-4 (DPC4) and Mothers against decapentaplegic homolog 4, SMAD4 is present in all metazoans and is highly conserved between species (16). As the main effector of TGF- $\beta$ signaling, SMAD4 has been found to be non-functional in more than half of adenocarcinomas of the pancreatic duct (17-19), and to varying degrees, in several other types of cancers (20-24). In many studies that have been conducted in the past 20 years it was found that the loss of SMAD4 function alone does not initiate a tumor, but it may promote the progression of tumors which have been initiated by other molecular defects, like the activation of KRas activation in the case of pancreatic duct adenocarcinoma and the inactivation of APC in colorectal cancer $(20,24)$. The loss of SMAD4 is playing a crucial role in the response to DNA damage with the consequence of increased genomic instability. This is very prominent in skin cancer and suggests a distinct role of SMAD4 in the progression of various types of tumors (25).

Screening large genes with multiples exons for mutations by traditional Sanger sequencing is slow, labor intensive and costly. Next-generation sequencing (NGS) in contrast allows the direct analysis of mutations in monogenic diseases at low cost without pre-screening. Novel DNA variants that have been identified by NGS still may be corroborated by Sanger sequencing before reporting them.

In this study, we performed NGS analysis based on multiplex PCR NGS for the investigation of SMAD4 mutations in HNSCC.

We found that mutations of SMAD4, as well as its expression level, are linked to the progression of HNSCC and affect patient survival. Moreover, we investigated the role of deleterious SMAD4 mutations to elucidate their role in HNSCC neoplasms.

\section{MATERIALS AND METHODS}

\section{Patients}

This study was approved by the Institutional Review Board of Mackay Memorial Hospital (approval number: 15MMHIS104). All patients provided written informed consent. Tumor samples were obtained from 122 patients undergoing HNSCC surgery (Supplementary Table 1). Cells were isolated from tissue sections by laser capture microdissection (LCM) following established protocols $(3,4)$. Additionally, $10 \mathrm{~mL}$ of whole blood was collected in the morning after fasting in Vacutainer tubes containing EDTA as the anticoagulant (Becton Dickson,
Franklin Lakes, NJ, USA) from each patient. None of the patients included in this study had received radiotherapy or adjuvant chemotherapy before surgery. DNA was extracted from blood and cancerous tissue as reported previously (26).

\section{SMAD4 Mutation Analysis by PCR-Based NGS}

Individual primer sets for 10 long PCR reactions were designed with Primer3 (version 0.4.0) (ELIXIR, funded by the European Commission) to amplify the entire coding sequence (exons 2-12) for human SMAD4 (Supplementary Table 2 and Supplementary Figure 1A). Amplicon concentrations were determined with the Qubit dsDNA HS Assay kit on a Qubit 2.0 fluorometer (Life Technologies, Carlsbad, CA, USA). PCR reactions were carried out using the KAPA LongRange HotStart kit (Kapa Biosystems, Wilmington, MA, USA). For library generation, long PCR products of each sample were pooled and then purified using Agencourt Ampure XP beads (Beckman Coulter, Pasadena, CA, USA). Indexed libraries of the pooled PCR products were prepared using the Illumina Nextera XT library preparation kit and then sequenced on the Illumina MiSeq system, following the manufacturer's instructions. Variant call format files were generated using the MiSeq Reporter software (version 2.3.32). The variants were further filtered on the basis of the following criteria: (1) DP $<30$, (2) genotype quality $<30$, (3) number of mismatches within a 40-bp window $\leq 3$, (4) mutant allele frequency of at least $10 \%$ in tumors and $<1 \%$ in normal cells, and (5) MAF in the 1000 Genomes Project and dbSNP137 > 1\%. The Integrative Genomics Viewer (IGV) was used to determine the read counts of the target amplicons and to confirm the detected variants. The mutation spectrum and lollipop figures for SMAD4 were generated with the OncoPrinter and MutationMapper tools available at cBioPortal $(27,28)$.

\section{Mutation Point Validation}

To validate the somatic mutations which were identified in the multiplex PCR-based NGS results, conventional Sanger sequencing was applied. Individual primer sets were designed in Primer3 (version 0.4.0), they have been listed in Supplementary Table 3. For Sanger sequencing, PCR reactions were performed with a standard hot start kit. Amplicons were sequenced with the ABI BigDye Terminator Cycle Sequencing kit on an ABI 3730xl DNA analyzer (Applied Biosystems, Foster City, CA, USA).

\section{Immunohistochemistry}

SMAD4 protein was visualized in tissue sections by immunohistochemistry, following previously reported protocols (29). In brief, 5- $\mu \mathrm{m}$-thick tissue sections were dewaxed, rehydrated, and then incubated with monoclonal mouse anti-human SMAD4 antibody (sc-7966, 1:100 dilution; Santa Cruz Biotechnology, Santa Cruz, CA, USA) in a humidification chamber at $4^{\circ} \mathrm{C}$ overnight. After rinsing with PBS, standard immunohistochemical staining was done using streptavidin-biotin complex system (Dako Corp.) with aminoethylcarbazole as the chromogen and subsequently counterstained with hematoxylin and mounted with Clearmount 


\section{A

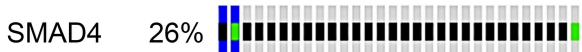

Synonymous Missense $\quad$ Loss of heterozygosity

B SMAD4

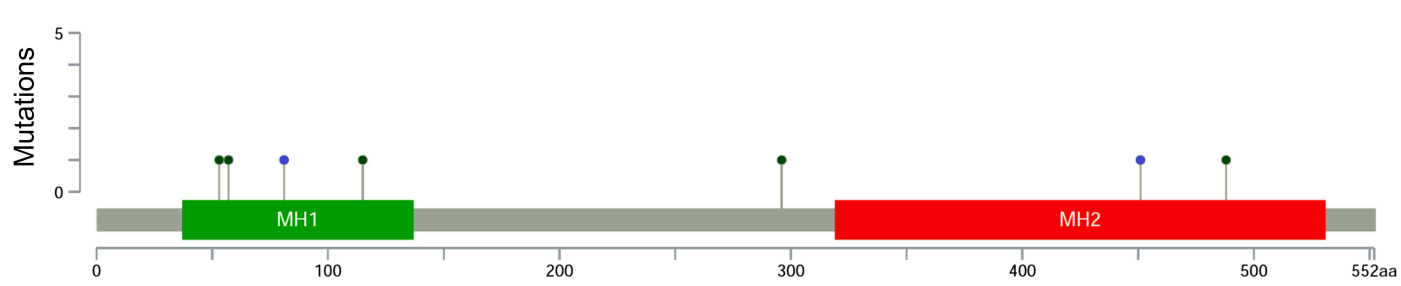

2 Synonymous 5 Missense

FIGURE 1 | SMAD4 mutations in patients with HNSCC. (A) Frequency of SMAD4 LOH, mutations, or both. Each column represents one patient. Colored boxes designate LOH status and mutation types. (B) Distribution of mutations in the sequence coding for SMAD4. Colored ovals represent mutation types, colored boxes represent domains. Colored boxes represent mutation types.

(Zymed Laboratories, Inc.). The primary antibody used was a Preimmune mouse IgG was used as a negative control. Normal epithelium adjacent to the tumor served as the internal positive control. Tumors containing $\geq 50 \%$ and $<50 \%$ positive cancer cells were classified to have high and low SMAD4 expression (30).

\section{Cell Culture, Reagents, and Phenotypic Assays}

In this study, the HNSCC cell lines SAS, OECM-1, HSC3, $\mathrm{FaDu}, \mathrm{SCC} 25, \mathrm{OC} 3$, and OC4 were used. Normal human oral keratinocytes (NOKs); served as controls. The cells were cultured as described previously (31). Our cell lines were authenticated by Mission Biotech (Nangang, Taipei, Taiwan) on August 8, 2017, using the Promega StemElite ID System and analyzed on ABI PRISM 3730 Genetic Analyzer with GeneMapper (version 3.7). si-SMAD4 and scramble control (si-control) oligonucleotides were purchased from Santa Cruz Biotech (Santa Cruz). For transfection, TransFectin Lipid Reagent (BioRad Lab., Hercules, CA, USA) was used. sh-SMAD4 vectors (TRCN0000010321) and a sh-Luc control vector (TRCN0000072249), packaged in lentiviruses, were purchased from National RNAi Core (Academia Sinica, Taipei, Taiwan). The cells were infected and selected using puromycin (Sigma-Aldrich) at $5.0 \mu \mathrm{g} / \mathrm{mL}$ for 7 days to establish stable subclones. Phenotypic events, including proliferation, migration, and invasion, were analyzed as previously described $(10,32)$.

\section{Analysis of SMAD4 Mutations in HNSCC Cell Lines}

All coding exons of SMAD4 in SAS, OECM-1, HSC3, FaDu, SCC25, OC3, and OC4 cells were amplified by PCR and then sequenced using the ABI BigDye Terminator Cycle Sequencing kit on an ABI 3730xl DNA analyzer (Applied Biosystems). The variants with MAF > $1 \%$ in the 1000 Genomes Project and dbSNP137 were filtered.

\section{Constructs}

The SMAD4 cDNA sequence was amplified from the cDNA of SAS cells with the primers SMAD4_Forward and SMAD4_Reverse, introducing BamHI and EcoRI sites for directional cloning. The PCR product then was subcloned into the pBabe puro vector. The p.H132Y, p.P296T, and p.A488V mutations were introduced into SMAD4 cDNA with the Q5 Site-Directed Mutagenesis kit (New England BioLabs, Ipswich, MA, USA) with the primers H132Ymut, P296Tmut, and A488Vmut. We named the resulting mutants p.H132Y, p.P296T, and p.A488V, respectively. Supplementary Table 3 lists the primers used in this section.

\section{Loss of Heterozygosity Analysis at the SMAD4 Locus}

Three polymorphic markers close to the SMAD4 locus (D18S363, D18S474, and D18S46) were used to analyze the loss of heterozygosity status $(\mathrm{LOH})$ of SMAD4. These markers are described in Supplementary Table 3. As templates, samples of genomic DNA ( 100 ng) were extracted from HNSCCs and matching normal tissues. The PCR reaction $(20 \mu \mathrm{L})$ contained $5 \times$ Phusion HF buffer, $200 \mu \mathrm{M}$ of each dNTP, $0.25 \mu \mathrm{M}$ of each marker, and $0.3 \mu \mathrm{l}$ (0.6 units) of Phusion High-Fidelity DNA Polymerase (Thermo Fisher Scientific, Vilnius, Lithuania). Amplification was performed under the following conditions: $98^{\circ} \mathrm{C}$ for $5 \mathrm{~min}$, followed by 35 cycles at $98^{\circ} \mathrm{C}$ for $20 \mathrm{~s}, 60^{\circ} \mathrm{C}$ for $15 \mathrm{~s}$, and $72^{\circ} \mathrm{C}$ for $30 \mathrm{~s}$. The final extension was at $72^{\circ} \mathrm{C}$ for $7 \mathrm{~min}$. The PCR product $(0.5 \mu \mathrm{L})$ was mixed with $0.5 \mu \mathrm{L}$ of GeneScan-600 LIZ dye Size Standard (Applied Biosystems) in $10 \mu \mathrm{L}$ of Hi-Di formamide (Applied Biosystems), denatured 
for $3 \mathrm{~min}$ at $95^{\circ} \mathrm{C}$, and then cooled on ice. The samples were separated by capillary electrophoresis with an ABI PRISM 96-capillary 3730xl DNA Analyzer (Applied Biosystems) and the results were analyzed using GeneMapper (version 3.7; Applied Biosystems). $\mathrm{LOH}$ was evaluated using the following formula: $\mathrm{LOH}=$ (height of tumor allele $2 /$ height of tumor allele 1)/(height of normal allele 2/height of normal allele 1). As described previously (33). When the height of the tumor alleles decreased by $>40 \%$, the calculated $\mathrm{LOH}$ became $>1.49$ or $<0.5$; thus, we considered this ratio to indicate $\mathrm{LOH}$ positivity (Supplementary Figure 1B). Homozygous cases were considered non-informative for $\mathrm{LOH}$.

\section{Western Blotting}

Western Blot analysis was performed as previously described (29). Equal amounts of protein $(30 \mu \mathrm{g})$ were loaded per lane. As primary antibodies anti-SMAD4 (diluted 1:500, Santa Cruz) and anti-GAPDH (diluted 1:5,000, Santa Cruz) antibodies were employed. For detection, an HRP-conjugated horse anti-mouse IgG was used as the secondary antibody (diluted 1:5,000; Cell signaling; Cell Signaling Technology, Danvers, MA, USA).

\section{Statistical Analysis}

Data are presented as the mean \pm SEM. Chi-square and $t$-tests were used. Overall survival (OS) was defined as the time between
A

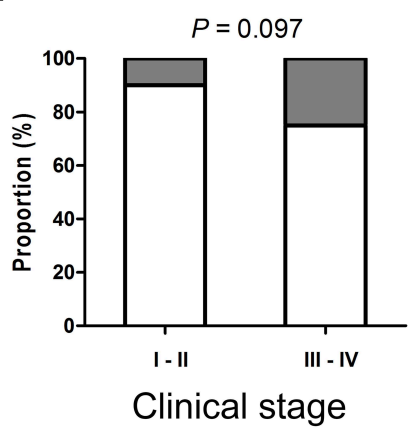

D

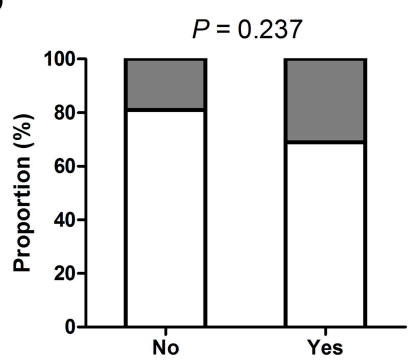

Perineural invasion

$\mathbf{F}$

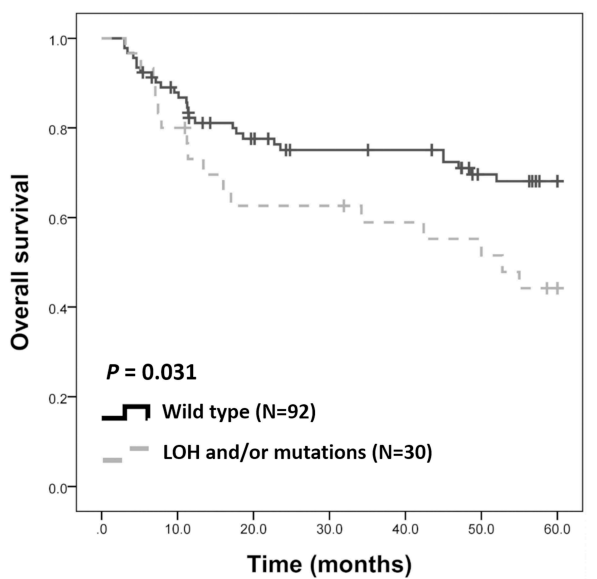

B

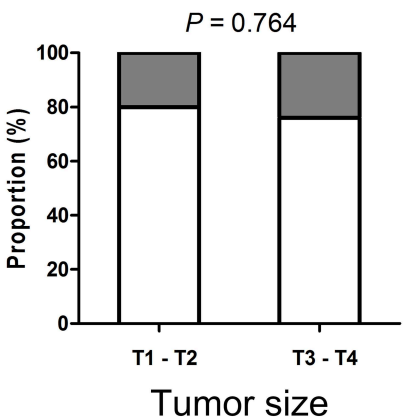

E

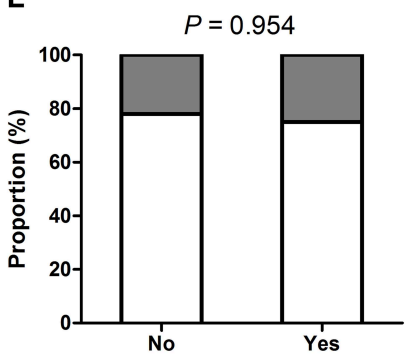

C

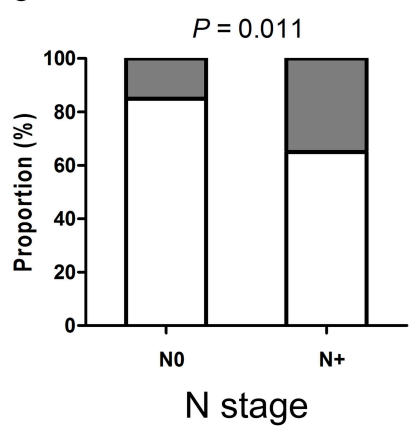

$\square \mathrm{LOH}$ and/or mutations $\square$ Wild type

\section{Lymphovascular permeation}

G

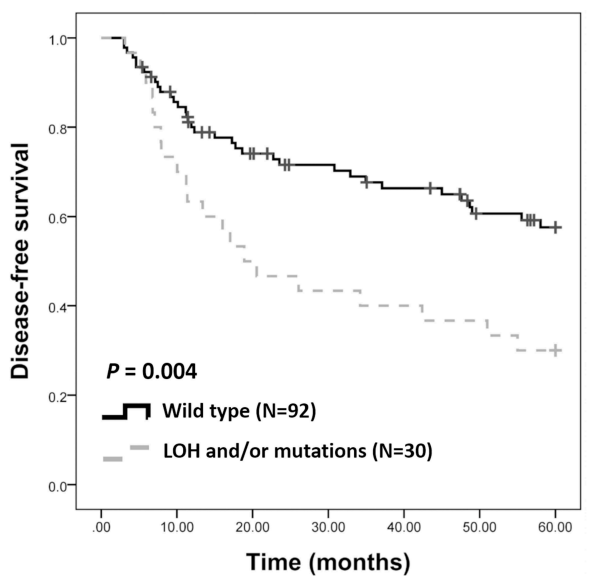

FIGURE 2 | SMAD4 LOH and mutations and clinical/pathological parameters. (A-E) Histograms are showing the association of SMAD4 LOH with mutation status and clinical stages (A), tumor size (B), N stage (C), perineural invasion (D), and lymphovascular permeation (E). (F,G) Kaplan-Meier analysis according to SMAD4 $\mathrm{LOH}$ and mutation status for OS (F) and DFS (G). 
the date of first diagnosis and the date of death or final followup. Disease-free survival (DFS) was defined as the time from the date of first diagnosis until the date of first recurrence or death. Patients without evidence of disease recurrence were censored at the final follow-up or death. Kaplan-Meier analysis was used to compare OS and DFS between the two groups. The multivariate Cox Proportional Hazards Model was used to assess the association of both OS and DFS with SMAD4 LOH, mutation status, and immunoexpression. Statistical significance was assumed to be indicated by ${ }^{*} P<0.05,{ }^{* *} P<0.01$, and ${ }^{* * *} P<0.001$ respectively. Cross-comparisons showing no statistically significant differences were not considered in further analysis.

\section{RESULTS}

\section{Somatic Mutations and LOH in SMAD4}

For the evaluation of the performance of SMAD4 in clinical assessments, 122 HNSCC samples were analyzed by multiplex PCR-based NGS and LOH analysis. We identified seven somatic mutations in the samples by NGS; of these, two were synonymous and five were missense mutations (Figures 1A,B, Supplementary Table 4). No hotspot region was found for SMAD4 mutations. The missense mutation p.Ala488Val, previously has been reported by Lee et al. (chr18:48604641) (34). Three polymorphic biomarkers (D18S474, D18S46, and D18S363) which are surrounding the SMAD4 locus were used to analyze LOH status. Percent $\mathrm{LOH}$ was $15.57 \%(19 / 122)$, $13.93 \%(17 / 122)$, and $13.11 \%(16 / 122)$ in D18S363, D18S46, and D18S474, respectively. In 28 (22.95\%) patients, LOH was detected in at least one of the three markers (Figure 1A), whereas $\mathrm{LOH}$ was noted in two or all three markers in 17 (13.93\%) patients.

Of the 122 patients, 32 (26.2\%) had SMAD4 LOH, mutations, or both, and the remaining 90 demonstrated no mutations or $\mathrm{LOH}$ (Figure 1A). The frequency of SMAD4 LOH was higher in patients with lymph node metastasis, mutations, or both compared to those where no metastasis was observed $(P=0.011$, Figure 2C). No significant differences were observed in the clinical stage, tumor size, perineural invasion, or lymphovascular permeation (Figures 2A-E, Supplementary Table 5). The Kaplan-Meier analysis indicated that patients with SMAD4 $\mathrm{LOH}$, mutations, or both had a significantly poorer OS and DFS than those with wild-type SMAD4 $(P=0.031$ and 0.004 , respectively; Figures 2F,G, respectively). Both univariate and adjusted multivariate Cox regression analyses revealed poor OS and DFS in patients with SMAD4 LOH, mutations, or both (OS hazard ratio [HR]: $1.95, P=0.034$; OS adjusted HR: 2.08, $P=0.024$; DFS HR: 2.08, $P=0.008$, DFS adjusted HR: 1.97 , $P=0.016$; Table 1).

\section{SMAD4 Expression in HNSCC Patients}

SMAD4 was detected in the cytoplasm and in the nuclei of basal and parabasal cells in normal oral epithelium which was adjacent to tumors (Figure 3A, top left). In tumor tissues, SMAD4 immunoreactivity varied from weak (Figure 3A, middle) to intense (Figure 3A, right). Low SMAD4 expression significantly correlated with the clinical stage $(P=0.004)$, tumor size $(P=0.020)$, and lymph node metastasis $(P=0.041$; Figures 3B-G and Supplementary Table 6). No differences were observed in SMAD4 expression in association with the $\mathrm{LOH}$ and mutation status, perineural invasion, and lymphovascular permeation. The Kaplan-Meier analysis revealed significantly poorer OS and DFS in patients when SMAD4 expression was low, compared to those with high SMAD4 expression $(P=0.033$ and $P=0.026$, respectively; Figures $3 \mathrm{H}, \mathbf{I}$, respectively). DFS was shorter in patients with when SMAD4 expression was low, as revealed by both univariate and adjusted multivariate Cox regression analysis. (HR: 4.43, $P=0.043$ and HR: 4.54, $P=0.046$, respectively; Table 1). Univariate Cox regression analysis showed that OS was poorer in patients with low SMAD4 expression (HR: 4.30, $P=0.047)$. However, after the multivariate Cox regression analysis, the correlation between SMAD4 expression and OS became only slightly significant (HR: $4.09, P=0.063$ ).

\section{Association Between SMAD4 Knockdown and Increased HNSCC Invasiveness}

The protein levels of SMAD4 in NOKs and HNSCC cells were determined by Western Blotting. As shown in Figure 4A, four of the seven (57.1\%) tested HNSCC cell lines had decreased or no protein expression of SMAD4, compared to NOKs. Interestingly, in SAS and OC3 cells the endogenous SMAD4 expression relative to the NOKs was elevated. No SMAD4 protein could be detected in FaDu cells (Figure 4A). These findings are in agreement with the already described homozygous deletion of SMAD4 in FaDu cells (35). The remaining two HNSCC cell lines (OC3 and HSC3 cells) were sequenced and two missense mutations were found (Supplementary Table 7) No mutation or LOH was found in OC4, OECM1, SAS, or SCC25 cells. OC3 and HSC3 which have missense mutation were excluded from further phenotype studies.

To further elucidate the oncogenic role of SMAD4 in HNSCC, we established stable SMAD4-knockdown SAS and SCC25 subclones. The knockdown effect was confirmed through Western blotting (Figure 4B). Cell proliferation was not affected by the knockdown of SMAD4 (Figures 4C,F), but HNSCC cell migration and invasion were significantly increased (Figures 4D,E,G,H). To corroborate this result, we transfected SAS and SCC25 cells with si-SMAD4 oligonucleotides (Supplementary Figure 2). Western blotting confirmed the si-SMAD4 knockdown effect on SMAD4 expression (Supplementary Figure 2A). Migration and invasion of HNSCC cells were significantly increased during the transient knockdown, but their proliferation behavior did not change (Supplementary Figures 2B-D). These results indicate that the mobility and invasiveness of HNSCC cells were enhanced by the knockdown of SMAD4.

\section{Association Between Mutations of SMAD4 With Increased Invasiveness in HNSCC}

To characterize the effects of SMAD4 on the phenotype, the full-length coding region of SMAD4 was amplified from SAS cells and cloned to generate the SMAD4 construct. In the tumor 
TABLE 1 | Univariate and Multivariate analysis of disease-free survival rate in HNSCC patients.

\begin{tabular}{|c|c|c|c|c|}
\hline Variables & HR $(95 \% \mathrm{Cl})$ & $P$ & Adjusted HR $(95 \% \mathrm{Cl})$ & $P$ \\
\hline \multicolumn{5}{|l|}{ Overall survival } \\
\hline \multicolumn{5}{|l|}{ SMAD4 LOH and mutations } \\
\hline Wild type & Reference & & Reference & \\
\hline LOH and/or mutations & $1.95(1.05-3.62)$ & $0.034^{*}$ & $2.08(1.10-3.92)$ & $0.024^{*}$ \\
\hline \multicolumn{5}{|l|}{ SMAD4 expression } \\
\hline \multicolumn{5}{|l|}{ Disease-free survival } \\
\hline \multicolumn{5}{|c|}{ SMAD4 LOH and mutations } \\
\hline Wild type & Reference & & Reference & \\
\hline $\mathrm{LOH}$ and/or mutations & $2.08(1.21-3.57)$ & $0.008^{\star}$ & $1.97(1.14-3.42)$ & $0.016^{\star}$ \\
\hline \multicolumn{5}{|l|}{ SMAD4 expression } \\
\hline
\end{tabular}

Adjusted for age, gender, and clinical stage.

HR, hazard ratio; Cl, confidence interval.

samples, three missense mutations were found (p.His132Tyr, p.Pro296Thr, and p.Ala488Val, Supplementary Table 4). These mutations are localized in the $\mathrm{MH} 1$, Linker, and $\mathrm{MH} 2$ domains, respectively (Figure 5A). By Sanger sequencing, we confirmed them as somatic mutations (Supplementary Figure 1C). We further made constructs for these mutations to be able to express these mutant proteins for further study. FaDu and OECM1 cells (which have no or only lowSMAD4 expression) were transfected with the SMAD4 vector and the mutant constructs. Western blotting was used to detect SMAD4 expression levels (Figures 5B,C). The exogenous SMAD4 expression reduced the migration and invasion of $\mathrm{FaDu}$ and OECM1 cells (Figures 5E,F,H,I). When the mutant p.H132Y was transfected, the phenotypes repressed by SMAD4 overexpression was abolished. The proliferation rates of the transfected cell lines were not affected (Figures 5D,G). However, transfection with p.P296T and p.A488V mutant constructs did not abolish the rescuing effects of SMAD4 overexpression on invasion and migration in HNSCC cells.

\section{DISCUSSION}

Varying rates of SMAD4 mutations have been detected in a wide range of cancers by large-scale exome sequencing. Compared with $35 \%$ of pancreatic cancer and $12 \%$ of colon cancer cases $(20$, 36-38), SMAD4 mutation in other types of cancers has occurred at lower rates. In COSMIC cohort studies, point mutations of SMAD4 were identified in $0.21,2.24,2.46$, and $8.86 \%$ of kidney, lung, esophagus, and biliary tract cancers, respectively $(24,38-$ 44). In general, 2.5 to $4 \%$ of the HNSCC tumors demonstrate the somatic mutation of SMAD4, making SMAD4 the fourth mutated gene in different types of cancers (8). In the study presented here, somatic SMAD4 mutations were found in $4.1 \%$ of HNSCC tumors we analyzed. This study is the first where somatic SMAD4 mutations in HNSCC were detected by multiplex PCRbased NGS. Besides, IGV was used to reconfirm all mutations.
Sanger sequencing confirmed three specific non-sense mutations. Thus, despite SMAD4 is a large gene that is coding for a 552amino acid polypeptide with a molecular weight of $60.439 \mathrm{Da}$, the current NGS-based strategy can be a reliable method for SMAD4 screening. No hotspot for mutations in the SMAD4 gene has been reported previously and we have not detected any was it observed in our study (8); therefore, allele-specific approaches that are targeting only common mutations $(45,46)$ are not suitable for the exploration of SMAD4 mutations in HNSCC. We have designed the multiplex PCR assay to generate SMAD4 amplicon libraries for sequencing. This includes protein-coding regions as well as conserved splice sites. Because this approach is highly scalable, it may provide advantages over Sanger sequencing regarding its potential application in routine clinical diagnostics, also because the labor required for analyzing individual samples for somatic SMAD4 mutations is low.

$S M A D$ proteins have two evolutionarily conserved regions separated by a linker region, MAD homology 1 and 2 (MH1 and $\mathrm{MH} 2$, respectively). The $\mathrm{MH} 1$ domain at the $\mathrm{N} /$ terminus is responsible for sequence-specific DNA binding $(47,48)$, the roles of the $\mathrm{MH} 2$ domain are heteromerization and transactivation $(49,50)$. Besides, the MH2 region partially interferes with the DNA-binding function of the MH1 region (47, 50, 51). Mutations in the domain between L43 and R135 may reduce the ability of SMAD4 to bind DNA considerably, as a $\beta$-hairpin protein motif within this region is responsible for the interaction with DNA. Our results demonstrate that the whole MH1 domain is very sensitive to changes in its overall primary structure and that tumorigenic mutations within the area of L43 and R135 interfere with its capability to bind DNA (52). Kim et al. were the first to document a non-sense mutation of SMAD4 (GAA526TAA) in two cell lines derived from the same HNSCC patient (53). Reiss et al. reported a homozygous deletion which includes the SMAD4 gene locus in FaDu cells (54). Others have furthermore identified the SMAD4 mutation in this HNSCC cell line $(35,55)$. The results of our Western Blotting experiments verified that this mutation 
A

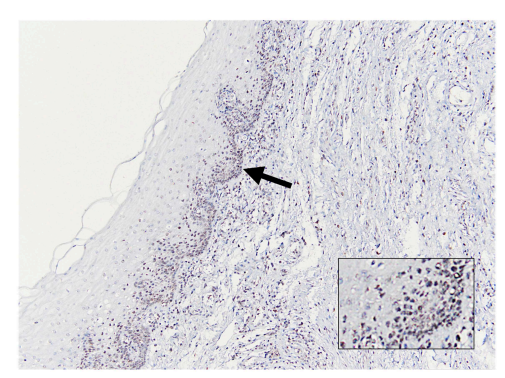

Adjacent oral mucosa

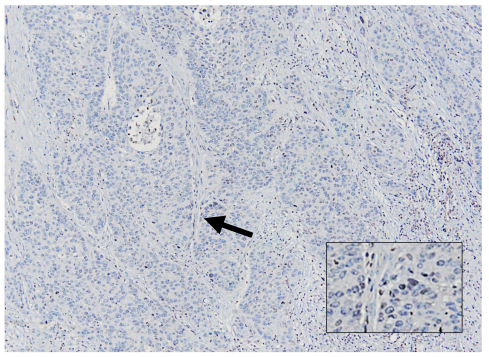

HNSCC (Low expression)

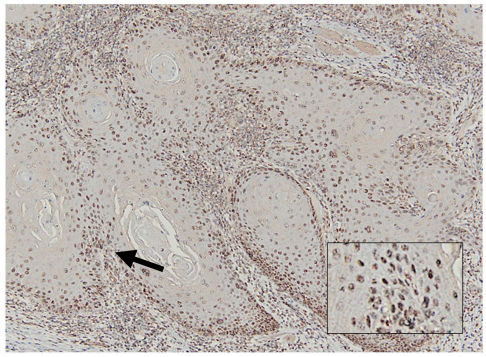

HNSCC (High expression)
B

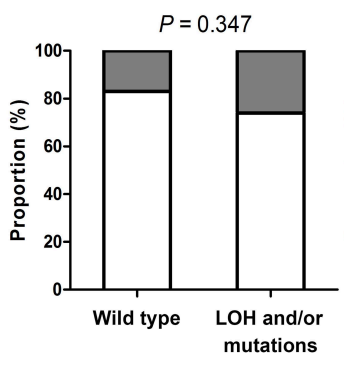

F

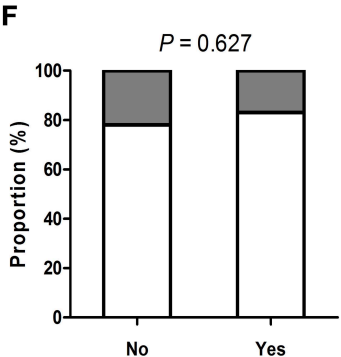

Perineural invasion

G

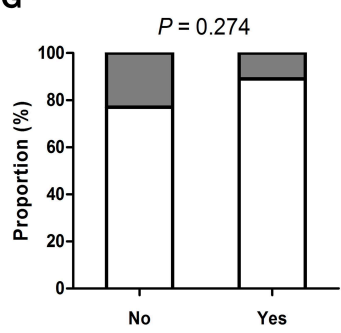

C

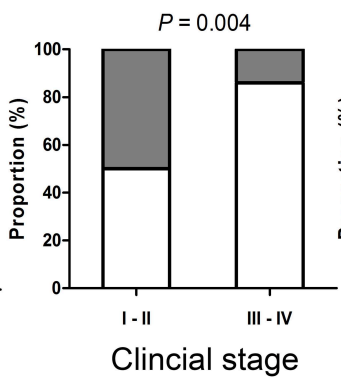

H
D

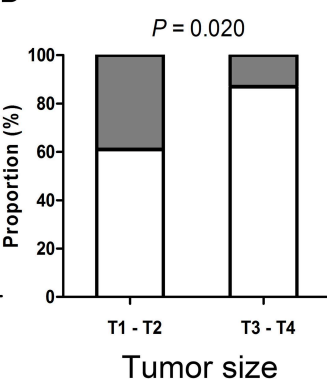

E

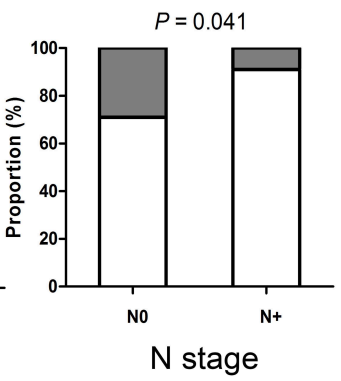

I $\square$ High SMAD4 $\square$ Low SMAD4

\section{Lymphovascular permeation}
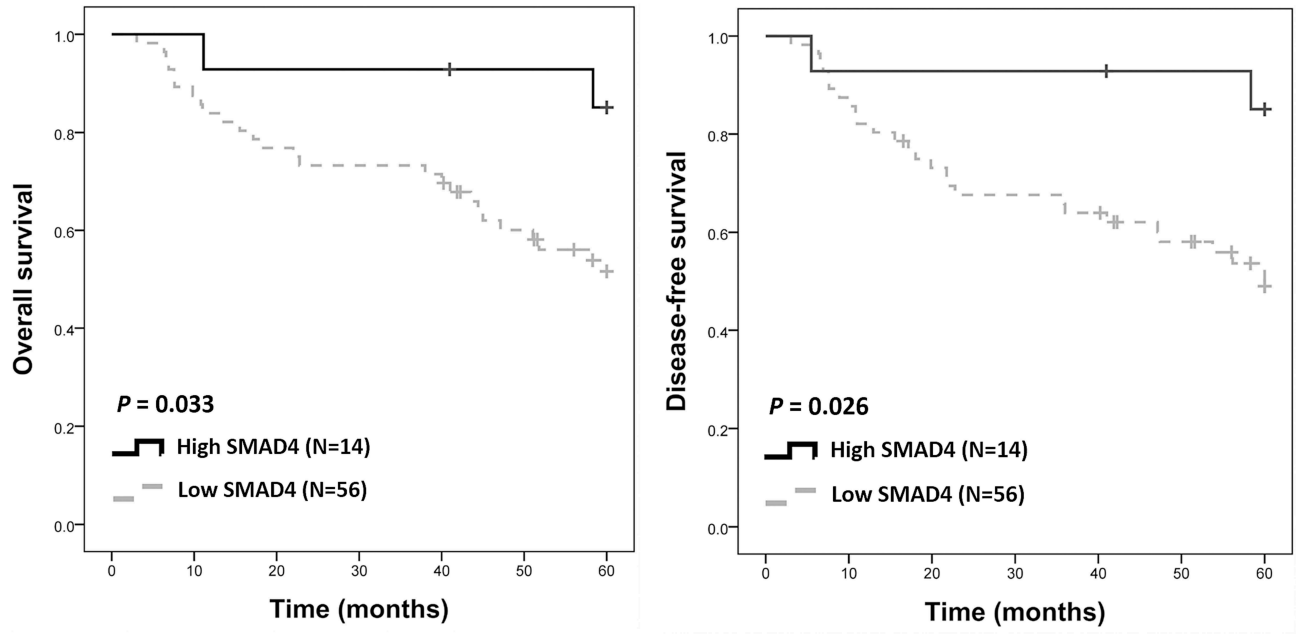

FIGURE 3 | SMAD4 immunoexpression and clinicopathological parameters. (A) Immunohistochemistry for SMAD4 in adjacent normal-appearing mucosa (left) and HNSCC tumor tissue (middle and right), as indicated. Tumor tissue showing low (middle), and high (right) SMAD4 staining. Arrows indicate enlarged area. Inset images enlarged by $300 \%$ relative to original image. (B-G) Histograms showing the association of SMAD4 immunoexpression with SMAD4 LOH and mutation status (B), clinical stage (C), tumor size (D), N stage (E), perineural invasion (F), and lymphovascular permeation (G). (H,I) Kaplan-Meier analysis according to SMAD4 immunoexpression for OS (H) and DFS (I).

which results in a nonsense mutation causes the complete loss of SMAD4 expression. This finding is consistent with previous observations that the majority of missense mutations outside of codons 330-370 inactivate SMAD4 through the degradation of the protein (56). These data are pointing out the important role SMAD4 is playing in HNSCC carcinogenesis (35). In this study, p.P296T and p.A488V mutant constructs did not abolish the rescuing effects of SMAD4 overexpression on the migration and invasion in HNSCC cells, suggesting that these mutations may have other functions, warranting further research.

The loss of SMAD4 protein contributes to an increase in genomic instability in the tumor epithelia. This effect, together with blocking the growth inhibition and apoptosis which normally are induced by TGF- $\beta$ but enhancing of 

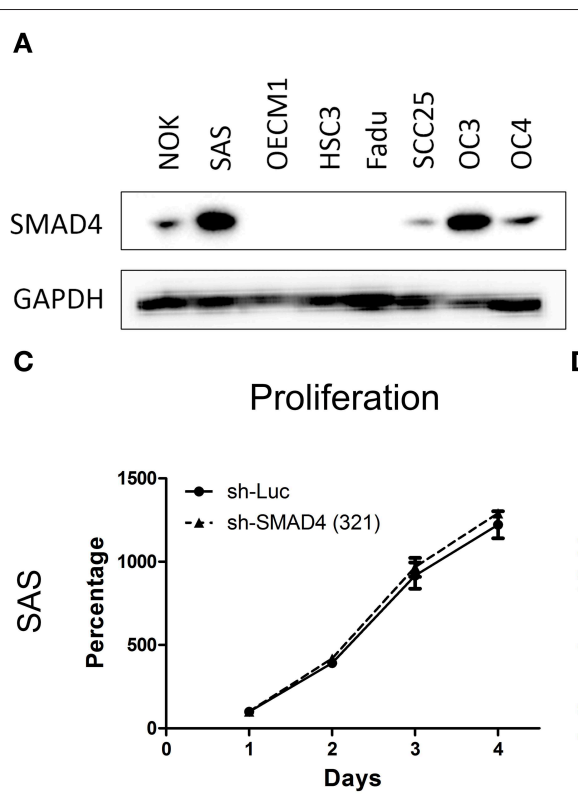

$\mathbf{F}$

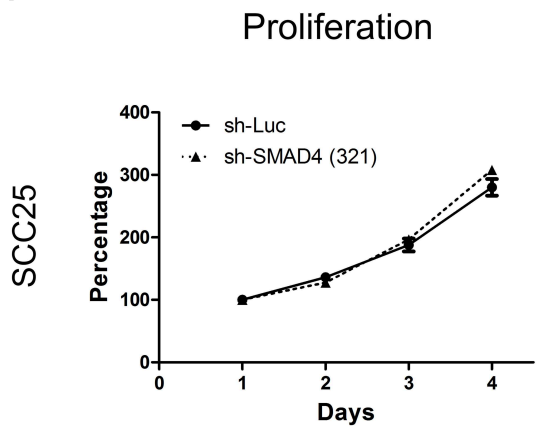

D

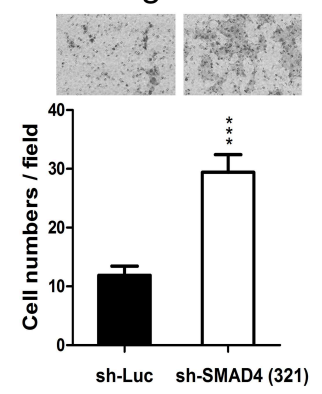

G
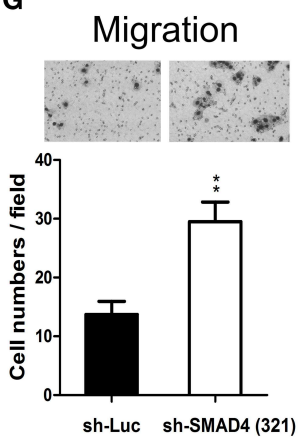

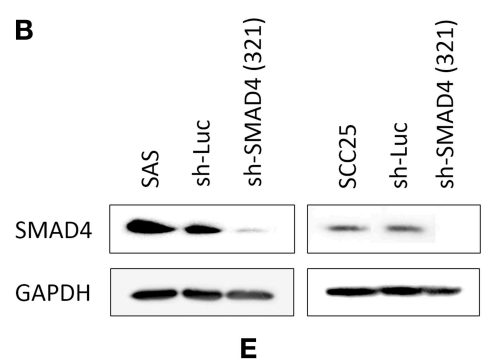

E

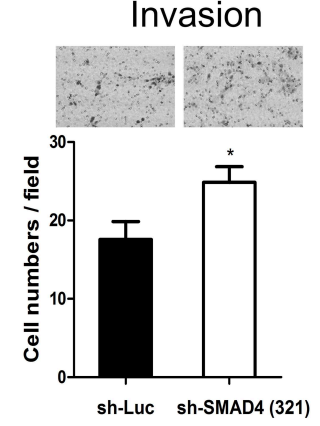

H

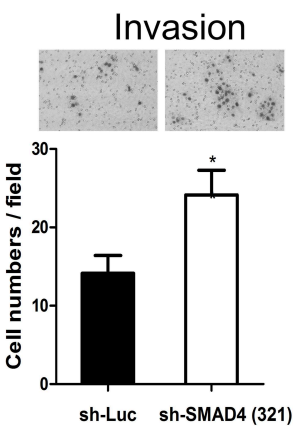

FIGURE 4 | Association of SMAD4 knockdown with oncogenic phenotypes in HNSCC cells. (A) Western blotting for SMAD4 expression in NOK cells and the seven HNSCC cell lines investigated. In SAS and SCC25 cells, SMAD4 expression levels are higher compared to other cell lines. (B) Western blotting on extracts from sh-Luc cell subclone (control) and sh-SMA1D4 (321) cell subclone, which was established from the construct TRCN0000010321. (C-E) SAS and (F-H) SCC25 cells: proliferation (C,F, respectively), migration ( $\mathbf{D}, \mathbf{G}$, respectively), and invasion $(\mathbf{E}, \mathbf{H}$, respectively).

TGF- $\beta$-mediated inflammation, could give way to the expansion of genetic defects cells during HNSCC tumorigenesis (57). SMAD4 expression may be a determinant of sensitivity/resistance to EGFR/MAPK or EGFR/JNK inhibition in HPV-negative HNSCC tumors (58). However, the studies on SMAD4 loss have reported highly inconsistent results $(30,59,60)$. Hernandez et al. developed a SMAD4 fluorescence in situ hybridization assay to measure chromosomal SMAD4 loss at the singlecell level in primary HNSCC samples and in and patientderived xenografted (PDX) HNSCC tumors (61). They found a heterozygous loss of SMAD4 in 35\% of primary HNSCCs and $41.3 \%$ of PDX tumors. Moreover, in $4.3 \%$ of the PDX tumors, the loss of SMAD4 was homozygous. Hernandez et al. also revealed intertumor and intratumor heterogeneities of SMAD4 chromosomal loss in HNSCCs $(60,61)$. In the study presented here, LCM was used to purify the cancerous tissue because LCM makes it possible to approximate the true gene profile of pure cancer cell subpopulations in the context of their actual tissue environment $(3,4)$. Combining LCM and NGS may be used to detect changes in the karyotype of neoplastic lesions of the oral epithelium.

Analyzing a region of chromosome $18 \mathrm{q}$ which has been found to be frequently lost in pancreatic cancers led to the identification of SMAD4 and the elucidation of its role in tumorigenesis (44), which was supported by the observation that germ-line SMAD4 mutations cause juvenile polyposis (JP), a condition which is characterized by the formation of intestinal polyps at young age and a cumulative lifetime risk for gastrointestinal cancer of 50\% (62). Breast cancers with mutations in the SMAD4 gene (63) are as sensitive to PARP inhibitors as BRCA-mutant breast or ovarian cancers. Similar challenges exist for lung cancers with SMAD4 (64), but a phenotype where SMAD4 has been lost has not yet been observed.

A convenient tool to confirm the oncogenic effects of mutated genes in question is the controlled expression of mutant constructs. The current study revealed that mutant SMAD4 can promote HNSCC tumorigenesis via cell migration and invasion. These data are concordant with the results of our clinical analysis, 
A

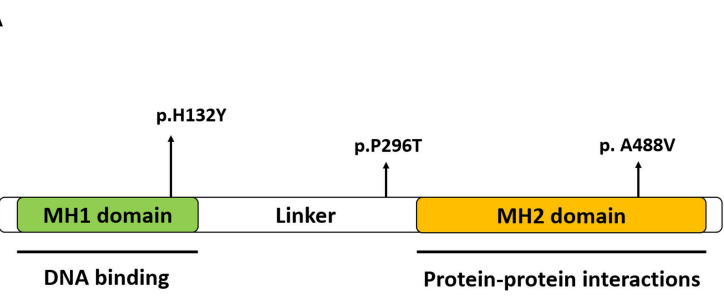

B

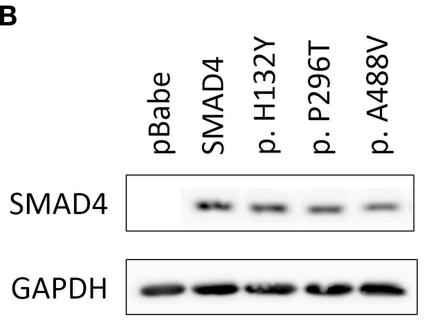

Fadu
C

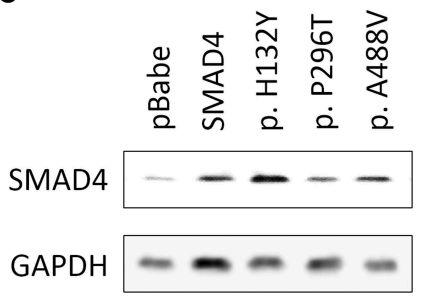

OECM1
D

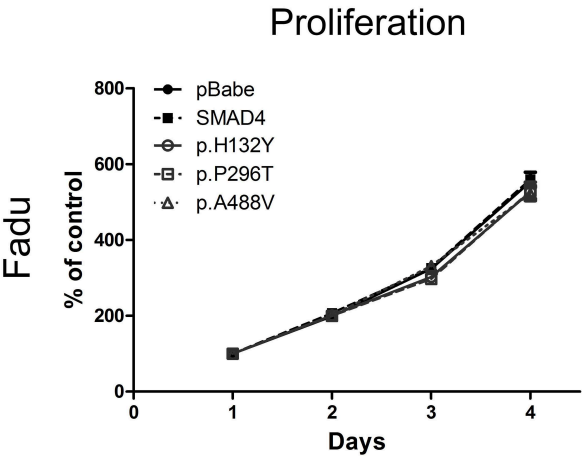

G

Proliferation

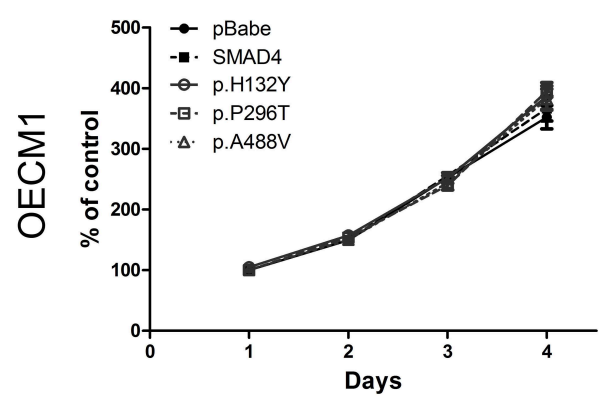

E

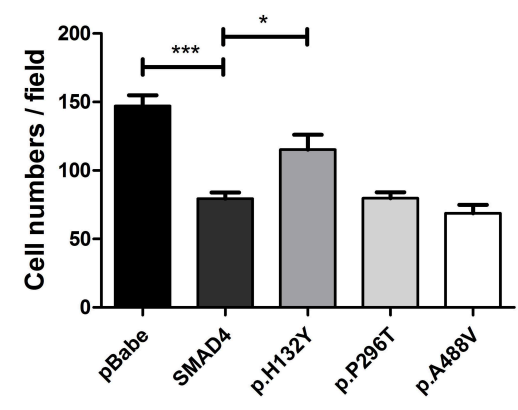

H
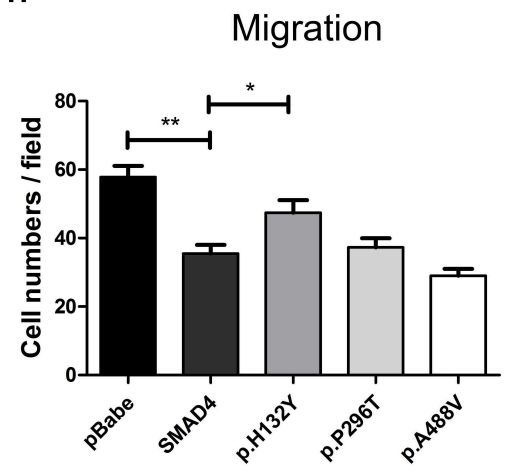

F

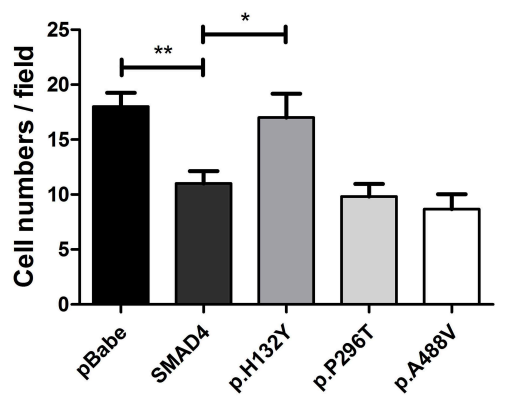

,

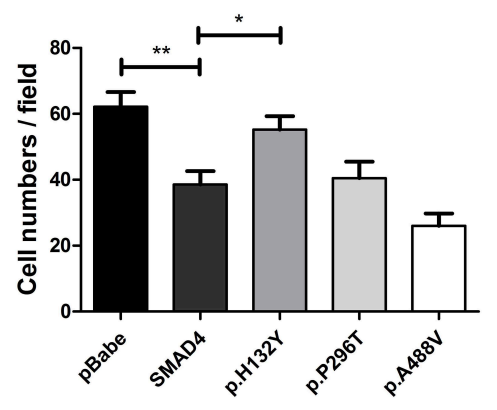

FIGURE 5 | Association of SMAD4 expression with oncogenic phenotypes in HNSCC cells. (A) Illustration of various SMAD4 constructs. Vertical arrows indicate the position of various mutations that were generated for this study. (B,D-F) FaDu and (C,G-I) OECM1 cells. Results of the Western blotting analysis. The cells were transfected with the vectors, and Western blotting was performed using an anti-SMAD4 antibody to detect the expression of exogenous SMAD4 proteins (B,C, respectively): Proliferation (D,G, respectively), migration (E,H, respectively), and invasion (F,I, respectively).

demonstrating more aggressive behavior and the potential for nodal metastasis of tumors with SMAD4 mutations. The mechanisms that cause diverse SMAD4 mutations, particularly missense mutations, confer loss-of-function to SMAD4.

In HNSCC, the region on chromosome $18 \mathrm{q}$ where SMAD4 is located is frequently lost at the genetic level in HNSCC (65). In esophageal cancer, the loss of SMAD4 correlates with the invasion depth and the pathologic stage (59) as well as with regional metastases and with decreased survival (30).In animal models for HNSCC, SMAD4 haploid insufficiency promoted tumor development (57). The loss of SMAD4 is contributing to increased genomic instability in the tumor epithelia. Defects in the signaling of SMAD family proteins are associated with an increased tendency for metastatic spread and regional or distant recurrence of HNSCC (66). Thus, inactivation of TGF- $\beta$ /SMAD signaling is frequently observed in HNSCC, and the inactivation of these signaling pathways might adversely affect patient outcomes. However, the location at which SMAD4 is downregulated in human HNSCCs and the causal role of SMAD4 LOH HNSCC development and progression remain unknown. We are the first to demonstrate that $\mathrm{LOH}$ and lower expression of SMAD4 can cause regional nodal metastasis and reduce the OS and DFS of HNSCC.

The inactivation of SMAD4 signaling is also associated with poorer prognosis in patients with adenocarcinoma of the pancreas and cancers of the esophagus $(23,43,67)$. When SMAD4 expression is lost in colorectal cancers (CRCs), it is associated with advanced stage disease, the presence of lymph 
node metastasis, and poor prognosis $(38,67,68)$. However, Kouvidou et al. failed to illustrate this relationship in colon cancer (69). Bacman et al. observed that missing nuclear expression of SMAD4 does not correlate with tumor grade or with the clinical outcome in colon cancer (70). Similar to CRCs, poor HNSCC-related patient outcomes are associated with $18 \mathrm{q} \mathrm{LOH}(71,72)$. SMAD4 depletion in an HNSCC cell line induces cetuximab resistance and results in worse survival in an orthotopic mouse model in vivo. JNK and MAPK activation as mediators of cetuximab resistance and provide the foundation for the concomitant EGFR and JNK/MAPK inhibition as a potential strategy for overcoming cetuximab resistance in HNSCCs with SMAD4 loss (58). However, in other studies, 18q loss did not appear to affect the survival of patients with HNSCCs $(73,74)$. This study indicates that LOH with SMAD4 mutations may significantly decrease the survival of patients with HNSCCs.

Our analysis results demonstrated an inverse correlation between somatic SMAD4 mutations and the downregulation of SMAD4 in HNSCCs, following other studies. Furthermore, the results of our studies demonstrate that SMAD4 loss due to mutations and downregulation results in increased tumor progression and recurrence rates. Moreover, SMAD4 mutation and loss, as well as low SMAD4 expression, worsened the OS. These factors may have led to the substantial differences between our and TCGA database's mutation profiles. Although the disparities warrant further resolution, the presented findings are congruent with those reported for other malignancies (75-77).

To summarize, HNSCC is highly heterogeneous at both the cellular and the genetic levels. The current findings show clearly that SMAD4 expression is suppressing the progression of HNSCC. Somatic mutations in SMAD4 and its expression determine the recurrence of HNSCC and go along with poor prognosis. Therefore, the proposed analysis of the genetic status may facilitate the identification of mutations in the SMAD4 gene as a novel diagnostic marker or therapeutic target in HNSCC and other head and neck cancers.

\section{DATA AVAILABILITY STATEMENT}

The data in this manuscript was submitted to Short Reads Archive under the BioProject accession PRJNA588804 and SRA Run Selector project (https://www.ncbi.nlm.nih.gov/Traces/ study/?acc=PRJNA588804\&o=acc_s\%3Aa).

\section{ETHICS STATEMENT}

The studies involving human participants were reviewed and approved by MacKay Memorial Hospital. The

\section{REFERENCES}

1. Ferlay J, Soerjomataram I, Dikshit R, Eser S, Mathers C, Rebelo M, et al. Cancer incidence and mortality worldwide: sources, methods and major patterns in GLOBOCAN 2012. Int J Cancer. (2015) 136:E359-86. doi: $10.1002 /$ ijc. 29210

2. Gupta S, Kong W, Peng Y, Miao Q, Mackillop WJ. Temporal trends in the incidence and survival of cancers of the upper aerodigestive tract in Ontario patients/participants provided their written informed consent to participate in this study.

\section{AUTHOR CONTRIBUTIONS}

C-JL: study design. C-JL, L-HL, and K-WC: data analysis. H-WC and L-HL: lab work. C-JL and K-WC: paper preparation.

\section{FUNDING}

This study was supported by grants from MacKay Memorial Hospital (MMH-E-105-12 and MMH-E108-12) and the Ministry of Science and Technology, Taiwan (MOST 108-2314-B-195-002-MY2 and MOST 105-2314-B-195-005-MY3).

\section{ACKNOWLEDGMENTS}

This manuscript was edited by Wallace Academic Editing.

\section{SUPPLEMENTARY MATERIAL}

The Supplementary Material for this article can be found online at: https://www.frontiersin.org/articles/10.3389/fonc. 2019.01379/full\#supplementary-material

Supplementary Figure 1 | Identification of SMAD4 mutations in HNSCC. (A) Schematic of five amplicons (blue arrows) covering exons 2-12 of SMAD4 for sequencing. (B) Representative fluorescent electropherograms for LOH marker D18S363 (left), D18S474 (middle), and D18S46 (right). Samples of genomic DNA that were extracted from tumors and matching normal tissues were used as templates. (C) Representative Sanger sequencing analysis of mutations p.His132Tyr, p.Pro296Thr, and p.Ala488Val. Upper panels, blood samples; lower panels, cancer samples. The arrows depict wild-type or mutated nucleotides.

Supplementary Figure 2 | Effect of si-SMAD4 transfection in HNSCC cells. (A) Western blotting for OC4 (left) and OECM1 (right) treated with 20 and 40-nM si-SMAD4 or control oligonucleotides for $48 \mathrm{~h}$ : (B) proliferation, (C) migration, and (D) invasion.

Supplementary Table 1 | Clinicopathological characteristics of the HNSCC patients $(n=122)$.

Supplementary Table 2 | List of long PCR primers used for amplification of SMAD4 gene.

Supplementary Table 3 | List of PCR primers used for PCR, sequencing, and construction, site directed mutagenesis, and SMAD4 LOH.

Supplementary Table 4 | List of SMAD4 mutations in HNSCC tumors.

Supplementary Table 5 | Clinical parameters and SMAD4 LOH and/or mutations in HNSCC patients $(n=122)$.

Supplementary Table 6 | Clinical parameter and SMAD4 expression in OSCC patients $(n=70)$.

Supplementary Table 7 | List of SMAD4 mutations in HNSCC cell lines.

and the United States. Int J Cancer. (2009) 125:2159-65. doi: 10.1002/ijc. 24533

3. Liu CJ, Lin SC, Chen YJ, Chang KM, Chang KW. Array-comparative genomic hybridization to detect genomewide changes in microdissected primary and metastatic oral squamous cell carcinomas. Mol Carcinog. (2006) 45:721-31. doi: $10.1002 / \mathrm{mc} .20213$

4. Liu CJ, Liu TY, Kuo LT, Cheng HW, Chu TH, Chang KW, et al. Differential gene expression signature between primary and metastatic head 
and neck squamous cell carcinoma. J Pathol. (2008) 214:489-97. doi: 10.1002/ path.2306

5. Lin SC, Chen YJ, Kao SY, Hsu MT, Lin CH, Yang SC, et al. Chromosomal changes in betel-associated oral squamous cell carcinomas and their relationship to clinical parameters. Oral Oncol. (2002) 38:266-73. doi: 10.1016/S1368-8375(01)00054-9

6. Cancer Genome Atlas Research N, Weinstein JN, Collisson EA, Mills GB, Shaw KR, Ozenberger BA, et al. The cancer genome atlas pan-cancer analysis project. Nat Genet. (2013) 45:1113-20. doi: 10.1038/ng.2764

7. Chang KW, Sarraj S, Lin SC, Tsai PI, Solt D. P53 expression, p53 and Ha-ras mutation and telomerase activation during nitrosaminemediated hamster pouch carcinogenesis. Carcinogenesis. (2000) 21:1441-51. doi: 10.1093/carcin/21.5.441

8. Agrawal N, Frederick MJ, Pickering CR, Bettegowda C, Chang K, Li $\mathrm{RJ}$, et al. Exome sequencing of head and neck squamous cell carcinoma reveals inactivating mutations in NOTCH1. Science. (2011) 333:1154-7. doi: $10.1126 /$ science. 1206923

9. Croce CM. Oncogenes and cancer. N Engl J Med. (2008) 358:502-11. doi: 10.1056/NEJMra072367

10. Liu CJ, Tsai MM, Hung PS, Kao SY, Liu TY, Wu KJ, et al. miR-31 ablates expression of the HIF regulatory factor FIH to activate the HIF pathway in head and neck carcinoma. Cancer Res. (2010) 70:1635-44. doi: 10.1158/0008-5472.CAN-09-2291

11. Gaykalova DA, Mambo E, Choudhary A, Houghton J, Buddavarapu $\mathrm{K}$, Sanford $\mathrm{T}$, et al. Novel insight into mutational landscape of head and neck squamous cell carcinoma. PLoS ONE. (2014) 9:e93102. doi: 10.1371/journal.pone.0093102

12. Stransky N, Egloff AM, Tward AD, Kostic AD, Cibulskis K, Sivachenko A, et al. The mutational landscape of head and neck squamous cell carcinoma. Science. (2011) 333:1157-60. doi: 10.1126/science.1208130

13. Pickering CR, Zhang J, Yoo SY, Bengtsson L, Moorthy S, Neskey $\mathrm{DM}$, et al. Integrative genomic characterization of oral squamous cell carcinoma identifies frequent somatic drivers. Cancer Discov. (2013) 3:770-81. doi: 10.1158/2159-8290.CD-12-0537

14. Cancer Genome Atlas N. Comprehensive genomic characterization of head and neck squamous cell carcinomas. Nature. (2015) 517:576-82. doi: $10.1038 /$ nature 14129

15. Kandoth C, McLellan MD, Vandin F, Ye K, Niu B, Lu C, et al. Mutational landscape and significance across 12 major cancer types. Nature. (2013) 502:333-9. doi: 10.1038/nature12634

16. Massague J. TGFbeta signalling in context. Nat Rev Mol Cell Biol. (2012) 13:616-30. doi: 10.1038/nrm3434

17. Wilentz RE, Iacobuzio-Donahue CA, Argani P, McCarthy DM, Parsons JL, Yeo CJ, et al. Loss of expression of Dpc4 in pancreatic intraepithelial neoplasia: evidence that DPC4 inactivation occurs late in neoplastic progression. Cancer Res. (2000) 60:2002-6. Retrieved from: https://cancerres.aacrjournals.org/ content/60/7/2002

18. Gu G, Dubauskaite J, Melton DA. Direct evidence for the pancreatic lineage: NGN3 + cells are islet progenitors and are distinct from duct progenitors. Development. (2002) 129:2447-57. Retrieved from: https://dev.biologists.org/ content/129/10/2447.long

19. Kawaguchi Y, Cooper B, Gannon M, Ray M, MacDonald RJ, Wright CV. The role of the transcriptional regulator Ptfla in converting intestinal to pancreatic progenitors. Nat Genet. (2002) 32:128-34. doi: 10.1038/ng959

20. Miyaki M, Iijima T, Konishi M, Sakai K, Ishii A, Yasuno M, et al. Higher frequency of Smad4 gene mutation in human colorectal cancer with distant metastasis. Oncogene. (1999) 18:3098-103. doi: 10.1038/sj.onc.1202642

21. Liao X, Hao Y, Zhang X, Ward S, Houldsworth J, Polydorides AD, et al. Clinicopathological characterization of SMAD4-mutated intestinal adenocarcinomas: a case-control study. PLoS ONE. (2019) 14:e0212142. doi: 10.1371/journal.pone.0212142

22. Ding Z, Wu CJ, Chu GC, Xiao Y, Ho D, Zhang J, et al. SMAD4-dependent barrier constrains prostate cancer growth and metastatic progression. Nature. (2011) 470:269-73. doi: 10.1038/nature09677

23. Haeger SM, Thompson JJ, Kalra S, Cleaver TG, Merrick D, Wang $\mathrm{XJ}$, et al. Smad4 loss promotes lung cancer formation but increases sensitivity to DNA topoisomerase inhibitors. Oncogene. (2016) 35:577-86. doi: $10.1038 /$ onc. 2015.112
24. Zhao M, Mishra L, Deng CX. The role of TGF-beta/SMAD4 signaling in cancer. Int J Biol Sci. (2018) 14:111-23. doi: 10.7150/ijbs.23230

25. Yang L, Mao C, Teng Y, Li W, Zhang J, Cheng X, et al. Targeted disruption of Smad4 in mouse epidermis results in failure of hair follicle cycling and formation of skin tumors. Cancer Res. (2005) 65:8671-8. doi: 10.1158/0008-5472.CAN-05-0800

26. Hung PS, Chang KW, Kao SY, Chu TH, Liu CJ, Lin SC. Association between the rs2910164 polymorphism in pre-mir$146 \mathrm{a}$ and oral carcinoma progression. Oral Oncol. (2012) 48:404-8. doi: 10.1016/j.oraloncology.2011.11.019

27. Gao J, Aksoy BA, Dogrusoz U, Dresdner G, Gross B, Sumer SO, et al. Integrative analysis of complex cancer genomics and clinical profiles using the cBioPortal. Sci Signal. (2013) 6:pl1. doi: 10.1126/scisignal.2004088

28. Cerami E, Gao J, Dogrusoz U, Gross BE, Sumer SO, Aksoy BA, et al. The cBio cancer genomics portal: an open platform for exploring multidimensional cancer genomics data. Cancer Discov. (2012) 2:401-4. doi: 10.1158/2159-8290.CD-12-0095

29. Chen YF, Yang CC, Kao SY, Liu CJ, Lin SC, Chang KW. MicroRNA211 enhances the oncogenicity of carcinogen-induced oral carcinoma by repressing TCF12 and increasing antioxidant activity. Cancer Res. (2016) 76:4872-86. doi: 10.1158/0008-5472.CAN-15-1664

30. Natsugoe S, Xiangming C, Matsumoto M, Okumura H, Nakashima S, Sakita $\mathrm{H}$, et al. Smad4 and transforming growth factor betal expression in patients with squamous cell carcinoma of the esophagus. Clin Cancer Res. (2002) 8:1838-42. Retrieved from: https://clincancerres.aacrjournals.org/ content/8/6/1838.long

31. Lin SC, Lin LH, Yu SY, Kao SY, Chang KW, Cheng HW, et al. FAT1 somatic mutations in head and neck carcinoma are associated with tumor progression and survival. Carcinogenesis. (2018) 39:1320-30. doi: 10.1093/carcin/ bgy107

32. Hung PS, Tu HF, Kao SY, Yang CC, Liu CJ, Huang TY, et al. miR31 is upregulated in oral premalignant epithelium and contributes to the immortalization of normal oral keratinocytes. Carcinogenesis. (2014) 35:116271. doi: 10.1093/carcin/bgu024

33. Demopoulos K, Arvanitis DA, Vassilakis DA, Siafakas NM, Spandidos DA. MYCL1, FHIT, SPARC, p16(INK4) and TP53 genes associated to lung cancer in idiopathic pulmonary fibrosis. J Cell Mol Med. (2002) 6:215-22. doi: 10.1111/j.1582-4934.2002.tb00188.x

34. Lee S, Cho YS, Shim C, Kim J, Choi J, Oh S, et al. Aberrant expression of Smad4 results in resistance against the growth-inhibitory effect of transforming growth factor-beta in the SiHa human cervical carcinoma cell line. Int $J$ Cancer. (2001) 94:500-7. doi: 10.1002/ijc.1494

35. Qiu W, Schonleben F, Li X, Su GH. Disruption of transforming growth factor beta-Smad signaling pathway in head and neck squamous cell carcinoma as evidenced by mutations of SMAD2 and SMAD4. Cancer Lett. (2007) 245:163-70. doi: 10.1016/j.canlet.2006.01.003

36. Rozenblum E, Schutte M, Goggins M, Hahn SA, Panzer S, Zahurak M, et al. Tumor-suppressive pathways in pancreatic carcinoma. Cancer Res. (1997) 57:1731-4.

37. Yatsuoka T, Sunamura M, Furukawa T, Fukushige S, Yokoyama T, Inoue $\mathrm{H}$, et al. Association of poor prognosis with loss of $12 \mathrm{q}$, $17 \mathrm{p}$, and $18 \mathrm{q}$, and concordant loss of $6 \mathrm{q} / 17 \mathrm{p}$ and $12 \mathrm{q} / 18 \mathrm{q}$ in human pancreatic ductal adenocarcinoma. Am J Gastroenterol. (2000) 95:2080-5. doi: 10.1111/j.1572-0241.2000.02171.x

38. Chang YC, Chang JG, Liu TC, Lin CY, Yang SF, Ho CM, et al. Mutation analysis of 13 driver genes of colorectal cancer-related pathways in Taiwanese patients. World J Gastroenterol. (2016) 22:2314-25. doi: 10.3748/wjg.v22.i7.2314

39. Martin D, Abba MC, Molinolo AA, Vitale-Cross L, Wang Z, Zaida M, et al. The head and neck cancer cell oncogenome: a platform for the development of precision molecular therapies. Oncotarget. (2014) 5:8906-23. doi: 10.18632/oncotarget.2417

40. India Project Team of the International Cancer Genome C. Mutational landscape of gingivo-buccal oral squamous cell carcinoma reveals new recurrently-mutated genes and molecular subgroups. Nat Commun. (2013) 4:2873. doi: $10.1038 /$ ncomms 3873

41. Kim KT, Kim BS, Kim JH. Association between FAT1 mutation and overall survival in patients with human papillomavirus-negative head and 
neck squamous cell carcinoma. Head Neck. (2016) 38(Suppl. 1):E2021-9. doi: 10.1002/hed.24372

42. Chen SJ, Liu H, Liao CT, Huang PJ, Huang Y, Hsu A, et al. Ultra-deep targeted sequencing of advanced oral squamous cell carcinoma identifies a mutation-based prognostic gene signature. Oncotarget. (2015) 6:18066-80. doi: $10.18632 /$ oncotarget. 3768

43. Blackford A, Serrano OK, Wolfgang CL, Parmigiani G, Jones S, Zhang $\mathrm{X}$, et al. SMAD4 gene mutations are associated with poor prognosis in pancreatic cancer. Clin Cancer Res. (2009) 15:4674-9. doi: 10.1158/1078-0432.CCR-09-0227

44. Hahn SA, Schutte M, Hoque AT, Moskaluk CA, da Costa LT, Rozenblum E, et al. DPC4, a candidate tumor suppressor gene at human chromosome 18q21.1. Science. (1996) 271:350-3. doi: 10.1126/science.271.5247.350

45. Nakaya K, Yamagata HD, Arita N, Nakashiro KI, Nose M, Miki T, et al. Identification of homozygous deletions of tumor suppressor gene FAT in oral cancer using CGH-array. Oncogene. (2007) 26:5300-8. doi: 10.1038/sj.onc. 1210330

46. Chosdol K, Misra A, Puri S, Srivastava T, Chattopadhyay P, Sarkar C, et al. Frequent loss of heterozygosity and altered expression of the candidate tumor suppressor gene 'FAT' in human astrocytic tumors. BMC Cancer. (2009) 9:5. doi: 10.1186/1471-2407-9-5

47. Kim J, Johnson K, Chen HJ, Carroll S, Laughon A. Drosophila Mad binds to DNA and directly mediates activation of vestigial by Decapentaplegic. Nature. (1997) 388:304-8. doi: 10.1038/40906

48. Zawel L, Dai JL, Buckhaults P, Zhou S, Kinzler KW, Vogelstein B, et al. Human Smad3 and Smad4 are sequence-specific transcription activators. Mol Cell. (1998) 1:611-7. doi: 10.1016/S1097-2765(00)80061-1

49. Shi Y, Hata A, Lo RS, Massague J, Pavletich NP. A structural basis for mutational inactivation of the tumour suppressor Smad4. Nature. (1997) 388:87-93. doi: $10.1038 / 40431$

50. Dai JL, Turnacioglu KK, Schutte M, Sugar AY, Kern SE. Dpc4 transcriptional activation and dysfunction in cancer cells. Cancer Res. (1998) 58:4592-7.

51. Hata A, Lo RS, Wotton D, Lagna G, Massague J. Mutations increasing autoinhibition inactivate tumour suppressors Smad2 and Smad4. Nature. (1997) 388:82-7. doi: 10.1038/40424

52. Jones JB, Kern SE. Functional mapping of the MH1 DNA-binding domain of DPC4/SMAD4. Nucleic Acids Res. (2000) 28:2363-8. doi: $10.1093 / \mathrm{nar} / 28.12 .2363$

53. Kim SK, Fan Y, Papadimitrakopoulou V, Clayman G, Hittelman WN, Hong WK, et al. DPC4, a candidate tumor suppressor gene, is altered infrequently in head and neck squamous cell carcinoma. Cancer Res. (1996) 56:2519-21.

54. Reiss M, Santoro V, de Jonge RR, Vellucci VF. Transfer of chromosome 18 into human head and neck squamous carcinoma cells: evidence for tumor suppression by Smad4/DPC4. Cell Growth Differ. (1997) 8:407-15.

55. Ikediobi ON, Davies H, Bignell G, Edkins S, Stevens C, O'Meara S, et al. Mutation analysis of 24 known cancer genes in the NCI-60 cell line set. Mol Cancer Ther. (2006) 5:2606-12. doi: 10.1158/1535-7163.MCT-06-0433

56. Thiagalingam S, Lengauer C, Leach FS, Schutte M, Hahn SA, Overhauser J, et al. Evaluation of candidate tumour suppressor genes on chromosome 18 in colorectal cancers. Nat Genet. (1996) 13:343-6. doi: 10.1038/ng0796-343

57. Bornstein S, White R, Malkoski S, Oka M, Han G, Cleaver T, et al. Smad4 loss in mice causes spontaneous head and neck cancer with increased genomic instability and inflammation. J Clin Invest. (2009) 119:3408-19. doi: 10.1172/JCI38854

58. Ozawa H, Ranaweera RS, Izumchenko E, Makarev E, Zhavoronkov A, Fertig EJ, et al. SMAD4 loss is associated with cetuximab resistance and induction of MAPK/JNK activation in head and neck cancer cells. Clin Cancer Res. (2017) 23:5162-75. doi: 10.1158/1078-0432.CCR-16-1686

59. Fukuchi M, Masuda N, Miyazaki T, Nakajima M, Osawa H, Kato H, et al. Decreased Smad4 expression in the transforming growth factor-beta signaling pathway during progression of esophageal squamous cell carcinoma. Cancer. (2002) 95:737-43. doi: 10.1002/cncr.10727

60. Xie W, Aisner S, Baredes S, Sreepada G, Shah R, Reiss M. Alterations of Smad expression and activation in defining 2 subtypes of human head and neck squamous cell carcinoma. Head Neck. (2013) 35:76-85. doi: 10.1002/hed.22924

61. Hernandez AL, Wang Y, Somerset HL, Keysar SB, Aisner DL, Marshall $\mathrm{C}$, et al. Inter- and intra-tumor heterogeneity of SMAD4 loss in head and neck squamous cell carcinomas. Mol Carcinog. (2019) 58:666-73. doi: $10.1002 / \mathrm{mc} .22958$
62. Zbuk KM, Eng C. Hamartomatous polyposis syndromes. Nat Clin Pract Gastroenterol Hepatol. (2007) 4:492-502. doi: 10.1038/ncpgasthep0902

63. Zhong D, Morikawa A, Guo L, Colpaert C, Xiong L, Nassar A, et al. Homozygous deletion of SMAD4 in breast cancer cell lines and invasive ductal carcinomas. Cancer Biol Ther. (2006) 5:601-7. doi: 10.4161/cbt.5.6.2660

64. Nagatake M, Takagi Y, Osada H, Uchida K, Mitsudomi T, Saji S, et al. Somatic in vivo alterations of the DPC4 gene at 18q21 in human lung cancers. Cancer Res. (1996) 56:2718-20.

65. Snijders AM, Schmidt BL, Fridlyand J, Dekker N, Pinkel D, Jordan RC, et al. Rare amplicons implicate frequent deregulation of cell fate specification pathways in oral squamous cell carcinoma. Oncogene. (2005) 24:4232-42. doi: $10.1038 /$ sj.onc. 1208601

66. Xie W, Bharathy S, Kim D, Haffty BG, Rimm DL, Reiss M. Frequent alterations of Smad signaling in human head and neck squamous cell carcinomas: a tissue microarray analysis. Oncol Res. (2003) 14:61-73. doi: $10.3727 / 000000003108748612$

67. Jia X, Shanmugam C, Paluri RK, Jhala NC, Behring MP, Katkoori VR, et al. Prognostic value of loss of heterozygosity and sub-cellular localization of SMAD4 varies with tumor stage in colorectal cancer. Oncotarget. (2017) 8:20198-212. doi: 10.18632/oncotarget.15560

68. Xie W, Rimm DL, Lin Y, Shih WJ, Reiss M. Loss of Smad signaling in human colorectal cancer is associated with advanced disease and poor prognosis. Cancer J. (2003) 9:302-12. doi: 10.1097/00130404-200307000-00013

69. Kouvidou C, Latoufis C, Lianou E, Kouvatseas G, Kakouri E, Anagnostakis D, et al. Expression of Smad4 and TGF-beta2 in colorectal carcinoma. Anticancer Res. (2006) 26:2901-7. Retrieved from: http://ar.iiarjournals.org/content/26/ $4 \mathrm{~B} / 2901$

70. Bacman D, Merkel S, Croner R, Papadopoulos T, Brueckl W, Dimmler A. TGF-beta receptor 2 downregulation in tumour-associated stroma worsens prognosis and high-grade tumours show more tumour-associated macrophages and lower TGF-betal expression in colon carcinoma: a retrospective study. BMC Cancer. (2007) 7:156. doi: 10.1186/1471-2407-7-156

71. Pearlstein RP, Benninger MS, Carey TE, Zarbo RJ, Torres FX, Rybicki BA, et al. Loss of $18 \mathrm{q}$ predicts poor survival of patients with squamous cell carcinoma of the head and neck. Genes Chromosomes Cancer. (1998) 21:3339. doi: 10.1002/(SICI)1098-2264(199804)21:4<;333::AID-GCC7>;3.0.CO;2-\#

72. Kelker W, Van Dyke DL, Worsham MJ, Christopherson PL, James CD, Conlon MR, et al. Loss of 18q and homozygosity for the DCC locus: possible markers for clinically aggressive squamous cell carcinoma. Anticancer Res. (1996) 16:2365-72.

73. Choi HR, Roberts DB, Johnigan RH, Sturgis EM, Rosenthal DI, Weber RS, et al. Molecular and clinicopathologic comparisons of head and neck squamous carcinoma variants: common and distinctive features of biological significance. Am J Surg Pathol. (2004) 28:1299-310. doi: 10.1097/01.pas.0000138003.46650.dc

74. Ng IO, Xiao L, Lam KY, Yuen PW, Ng M. Microsatellite alterations in squamous cell carcinoma of the head and neck-clustering of loss of heterozygosity in a distinct subset. Oral Oncol. (2000) 36:484-90. doi: 10.1016/S1368-8375(00)00040-3

75. Morris LG, Kaufman AM, Gong Y, Ramaswami D, Walsh LA, Turcan S, et al. Recurrent somatic mutation of FAT1 in multiple human cancers leads to aberrant Wnt activation. Nat Genet. (2013) 45:253-61. doi: 10.1038/ng.2538

76. Wang L, Lyu S, Wang S, Shen H, Niu F, Liu X, et al. Loss of FAT1 during the progression from DCIS to IDC and predict poor clinical outcome in breast cancer. Exp Mol Pathol. (2016) 100:177-83. doi: 10.1016/j.yexmp.2015.12.012

77. Yu J, Li $\mathrm{H}$. The expression of FAT1 is associated with overall survival in children with medulloblastoma. Tumori. (2017) 103:44-52. doi: 10.5301/tt.5000570

Conflict of Interest: The authors declare that the research was conducted in the absence of any commercial or financial relationships that could be construed as a potential conflict of interest.

Copyright (C) 2019 Lin, Chang, Cheng and Liu. This is an open-access article distributed under the terms of the Creative Commons Attribution License (CC BY). The use, distribution or reproduction in other forums is permitted, provided the original author(s) and the copyright owner(s) are credited and that the original publication in this journal is cited, in accordance with accepted academic practice. No use, distribution or reproduction is permitted which does not comply with these terms. 